\title{
Water storage and subglacial drainage conditions inferred from borehole measurements on Gornergletscher, Valais, Switzerland
}

\author{
Almut Iken, Kristian Fabri ${ }^{*}$ and Martin Funk \\ Versuchsanslalt für Wasserbau, Hydrologie und Glaziologie, Eidgenössische Technische Hochschule, CH-8092 Zürich, Switzerland
}

\begin{abstract}
Measurements of change in length of a borehole, or displacements of poles and of subglacial water pressure were combined with drainage tests and electrode tests in boreholes, in experiments near the northern margin of Gornergletscher, Valais, Switzerland, at the upstream side of an overdeepening. The measurements suggest that the subglacial drainage system consisted of discrete conduits at that location, presumably linked cavities on "clean" bedrock. Changes in subglacial water pressure were followed by variations in subglacial water storage, together with similar variations in elevation of a pole. The variations in subglacial water storage caused changes in cross-sections of subglacial passageways and thereby changed the frequencies of slug-test oscillations. Similar experiments conducted near the center line of the glacier revealed different subglacial conditions: impeded drainage through a sediment layer, and different depths of water levels in different boreholes. These results are discussed in relation to previous studies.
\end{abstract}

\section{LIST OF SYMBOLS}

a Amplitude of oscillation

$A(x) \quad$ Cross-section of subglacial conduit

$b \quad$ Thickness of sediment layer

$D$ Constant in differential equation of oscillation, $D=\rho g$

$\Delta d \quad$ Change in thickness of the glacier by strain

$\Delta D \quad$ Deflection of glacier sole in center of cavity due to pressure increment $\Delta p$

E $\quad$ Elastic modulus

$F \quad$ Fraction of glacier bed covered by a water sheet

fr Friction factor

$g \quad$ Gravity $\left(+9.81 \mathrm{~m} \mathrm{~s}^{-1}\right)$

$h(R, t)$ Head, driving subglacial, radial flow from borehole $h_{0} \quad$ Unperturbed height of water level in borehole

$h_{1}(t) \quad$ Perturbation of height of water level

$\dot{h}_{1} \quad$ Time derivative of $h_{1}$

$K \quad$ Hydraulic conductivity $\left(\mathrm{m} \mathrm{s}^{-1}\right)$

$l$ Length of subglacial conduit, connecting borehole with reservoir of constant pressure

$\Delta l^{*} \quad$ Change in length of borehole by strain

$L \quad$ Weighted length of subglacial conduit (Equation (9))

$m$ Constant in differential equation of oscillation, $m=\rho\left(h_{0}+L\right)$

$n_{\mathrm{k}} \quad$ Kinematic porosity

$p \quad$ Pressure $(\mathrm{Pa})$

* Present address: Buchenweg 20, CH-4242 Laufen, Switzerland.
$\Delta p_{\mathrm{F}} \quad$ Pressure drop along a duct due to friction

$\dot{Q} \quad$ Discharge

$r \quad$ Radius of subglacial conduit

$r_{0} \quad$ Radius of borehole

$r_{\mathrm{F}} \quad$ Radius of borehole in sediment layer ("filter radius")

$R$ Distance from borehole (refers to radial subglacial flow)

$R_{l} \quad$ Distance from borehole where pressure remains constant during slug test

$R_{\mathrm{s}} \quad$ Radius of a circular cavity

$s \quad$ Length, measured along oscillating system

$S_{\mathrm{s}} \quad$ Specific storativity $\left(\mathrm{m}^{-1}\right)$

$\Delta s \quad$ Change in subglacial water storage (change in water volume per unit area of the bed $(\mathrm{mm})$ )

Time

$T \quad$ Period of oscillation

$u \quad$ Velocity in oscillating system (mean over crosssection)

$u_{\mathrm{s}} \quad$ Horizontal component of velocity of glacier at surface

$u_{\mathrm{d}} \quad$ Deformational contribution to $u_{\mathrm{s}}$

V Volume

$x \quad$ Horizontal coordinate

$z \quad$ Vertical coordinate (positive upward)

$\Delta z_{\mathrm{s}} \quad$ Vertical displacement of pole at glacier surface

$\Delta z_{\mathrm{b}} \quad$ Vertical displacement by sliding (while there is no water storage)

$\alpha \quad$ Compressibility of porous substance (sediment)

$\beta \quad$ Bed slope in sliding direction (mean over a distance comparable to that of magnetic ring from glacier bed) 
$\beta_{\mathrm{s}}, \beta_{1} \quad$ Compressibilities of rock and water, respectively

$\gamma \quad$ Dimensionless quantity, related to storage in sediments. $\gamma=\left(2 S_{\mathrm{s}} b r_{\mathrm{F}}{ }^{2}\right) / r_{0}{ }^{2}$

$\delta$ Damping constant (Equation C3, Appendix C)

$\eta \quad$ Dynamic viscosity of water

$\lambda \quad$ Logarithmic decrement (Equation (3))

$\nu \quad$ Poisson's ratio

$\rho \quad$ Density of water

$\omega \quad$ Frequency of oscillation

$\omega_{0}$

\section{INTRODUCTION}

Gornergletscher, Valais, Switzerland, is one of the largest glaciers in the Alps. It extends from an altitude of $4500 \mathrm{~m}$ to $2150 \mathrm{~m}$, the present position of the terminus. Below the confluence of its two largest tributaries, Grenzgletscher and Gornergletscher, the glacier flows through an overdeepening detected by A. Süsstrunk with seismicreflection methods in 1950 . (The bed contour lines are reproduced by Bearth (1953).) The present study was carried out on the upstream part of this overdeepening (Fig. 1), in the ablation area of the glacier.

A number of investigations have been carried out on Gornergletscher, of which several have been related to the sub-surface drainage conditions, for instance:

channel flow.

Tests on unsteady flow including a natural experiment: an outburst of the Gorner lake (Röthlisberger, 1980; H. Röthlisberger, unpublished data, 1979).

Records of electrical conductivity of the outlet stream (Collins, 1979).

Seasonal development of subglacial drainage and delivery of suspended sediment (Collins, 1989).

Seasonal variations of velocity (G. R. Elliston, unpublished data; H. Röthlisberger and others, unpublished data, 1974).

Diurnal variations of velocity (Iken, 1978).

Measurements of water levels in boreholes and a pilot study on water storage described below (Röthlisberger and others, 1979; H. Röthlisberger and others, unpublished data, 1979).

Dye tracing (Aschwanden and Leibundgut, 1982).

On the whole, the results of these studies suggest, or are compatible with, the notion of drainage through a few large ("Röthlisberger") channels, in contrast to neighboring Findelengletscher where drainage is believed to have taken place through numerous passageways or linked cavities. The difference shows up in:

Local differences of subglacial water pressure at

Tests on Röthlisberger's (1972) theory of steady

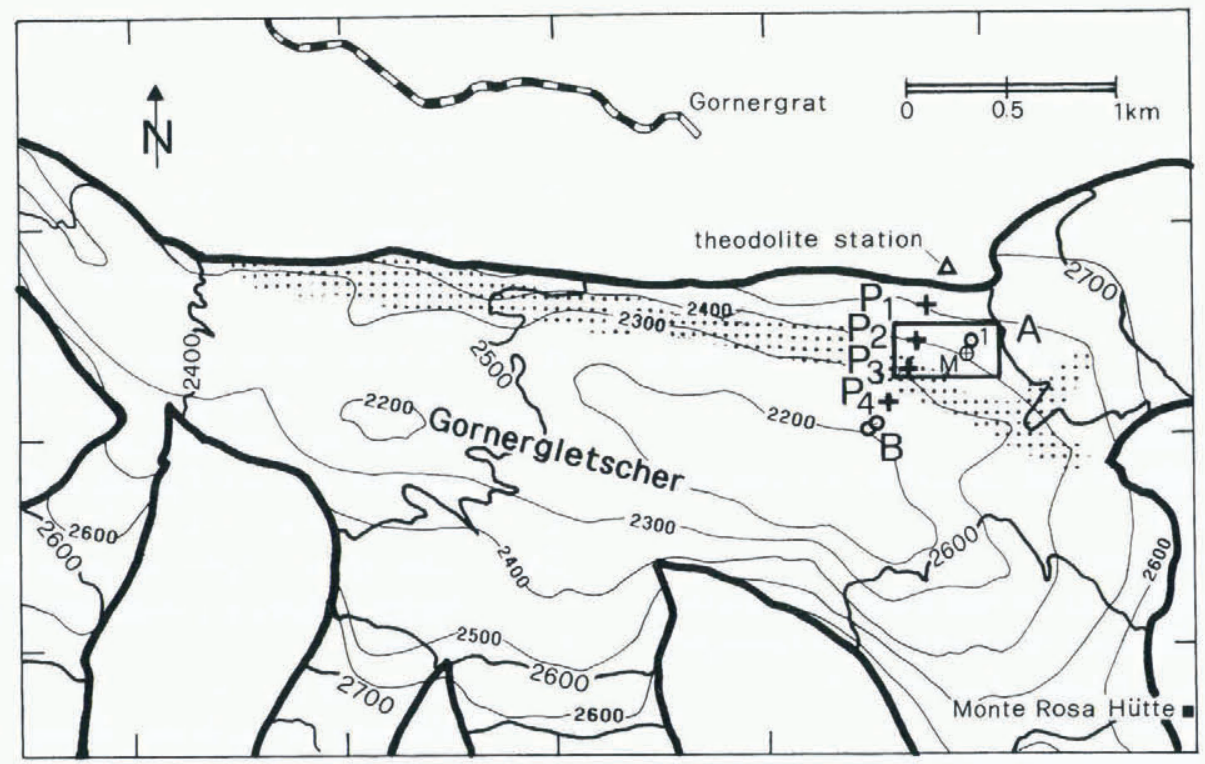

a

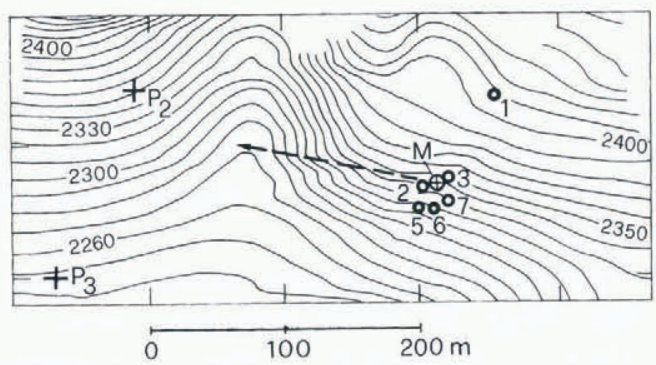

b
Fig. 1. (a) Map of study area on Gornergletscher. Heavy contours: surface elevation in 1988. Thin contours: bed elevation (after Süsstrunk (Bearth, 1953). In the study area, the bed is slightly deeper than is indicaled by the bed contours.) Contour interval $100 \mathrm{~m}$. Crosses indicate locations of poles $P_{I} P_{4}$, surveyed in 1979. The locations of the magnetic ring $(M)$ of hole 1 at sile $A$, and of two holes at site $B$ are also shown. (b) Enlarged section of (a) with bed contour lines, obtained by radio-echo sounding; contour interval $10 \mathrm{~m}$. The locations of boreholes 1-7, drilled in 1992, are also shown. The arrow indicates the direction of movement of the pole $(M)$ at the surface. 
Gornergletscher, whereas similar pressures were observed at different locations on Findelengletscher.

Smaller diurnal variations of velocity at Gornergletscher than at Findelengletscher.

Large phase shifts between variations of "subglacial" and "englacial" flow at Gornergletscher, but no phase shifts at Findelengletscher (Collins, 1979) ("englacial" means here "in large channels"; the channels may well be located at the bed).

In 1979, surveying of poles indicated that the vertical (upward) velocity increased substantially during a period of strong melt, similar to the "uplift" observed at Unteraargletscher (Iken and others, 1983). A pilot study of subglacial water storage, initiated by $\mathrm{H}$. Röthlisberger, suggested that the increase of vertical velocity of Gornergletscher was approximately equal to the rate of subglacial water storage (here and in the following, "subglacial water storage" denotes the volume stored per unit area of the bed). However, certain problems were encountered in the experimental procedure. Therefore, another attempt to determine subglacial water storage was made in the present study, together with other borehole investigations of subglacial conditions: electrode tests and slug tests. These experiments are described below.

\section{MEASUREMENTS OF LARGE-SGALE WATER STORAGE AT THE BED}

In 1979 a pilot study on subglacial water storage was carried out on Gornergletscher during a drilling operation, led by H. Röthlisberger. Following his suggestion, R. Bindschadler and one of the present authors carried out the following experiment.

A heatable (iron) wire was anchored at the bottom of a borehole which nearly extended to the glacier bed. The distance of the upper end of the wire from a reference mark on a pole, frozen into the ice, was measured while the wire was exposed to a certain, constant tension. Before a reading was taken the wire was heated electrically because it froze to the borehole wall between measurements. The position of the reference mark was surveyed with a precise theodolite. Figure 2 shows the vertical displacement of three poles $\mathrm{P}_{1}, \mathrm{P}_{2}$ and $\mathrm{P}_{3} ; \mathrm{P}_{2}$ is the pole with the reference mark. The location of these poles is shown in Figure 1.

Between 29 May and 4 June 1979, a period when much snow melted, both horizontal and vertical velocities of the poles increased. During these six days, pole $\mathrm{P}_{2}$ moved upward by $200 \mathrm{~mm}$ (Fig. 2). The other two poles experienced a similar but less marked uplift. Over the same period the upper end of the wire moved downward relative to the reference mark. The distance which the end of the wire moved corresponded to a thickness increase (vertical extension) of the glacier by about $100 \mathrm{~mm}$. (The contribution due to an increase in curvature and tilt of the hole was negligible.) The remainder of the upward displacement of the pole is the sum of subglacial water storage and the vertical component of the sliding motion, the latter assumed to be small. Discounting the vertical component of the sliding motion, the equivalent of a $100 \mathrm{~mm}$ thick water layer seems to have been stored beneath the glacier. However, a problem was encountered when the wire was melted free: if heated for too long, it melted deeper into the wall of the hole and thereby straightened. Consequently, its upper end could be pulled up a bit more. Heating was therefore kept to a minimum, but this problem sheds some doubt on the result.

The experiment was repeated with a different technique in 1992. A magnetic ring was anchored $10 \mathrm{~m}$ above the bed in a borehole. The distance between the ring and a reference mark on a pole at the surface was measured with a magnetic probe on a calibrated cable. A light and sound are triggered at the electronic device on the surface when the probe passes the ring. This equipment is commercially available. Repeated readings indicate tolerances of $0.5-1.0 \mathrm{~mm}$. The cumulative change in distance between magnetic ring and reference mark, $\Delta l^{*}$, is plotted in Figure $3 \mathrm{~b}$ as a function of time.

The angular displacements of the reference mark were surveyed at least daily with a theodolite, mounted on a short, insulated tube which was cemented into rock at the northern margin. Angular displacements were converted into elevation changes and horizontal displacements, based on a few additional measurements with an electronic distance meter. Cumulative change in elevation with time is plotted in Figure 3a. Standard deviations of repeated readings were in general equivalent to

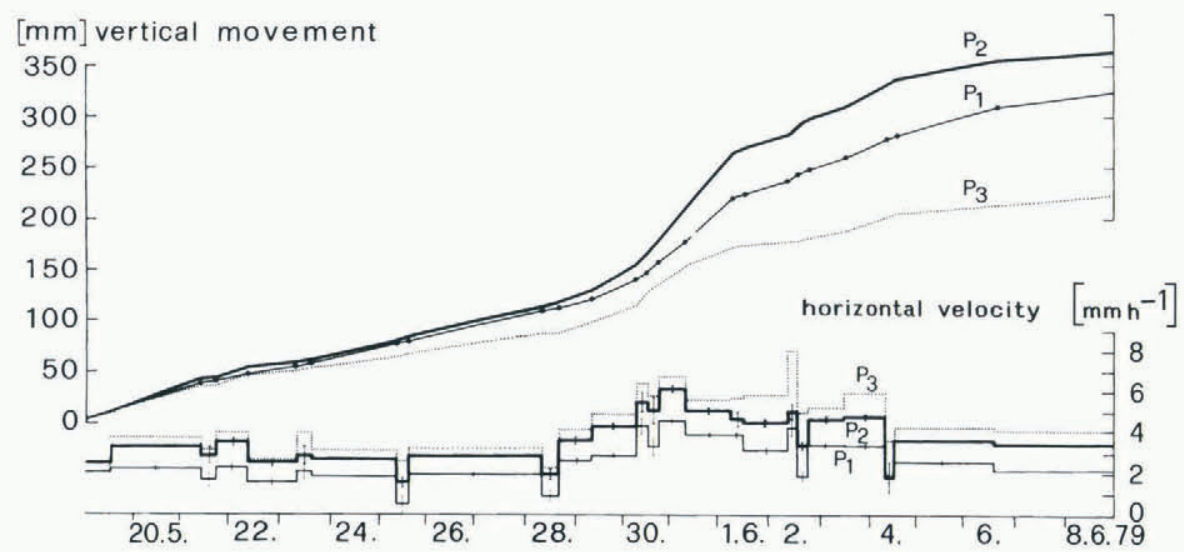

Fig. 2. Vertical displacement and horizontal velocity of poles $P_{1} P_{3}$ in 1979. Error bars refer to repeated readings. 


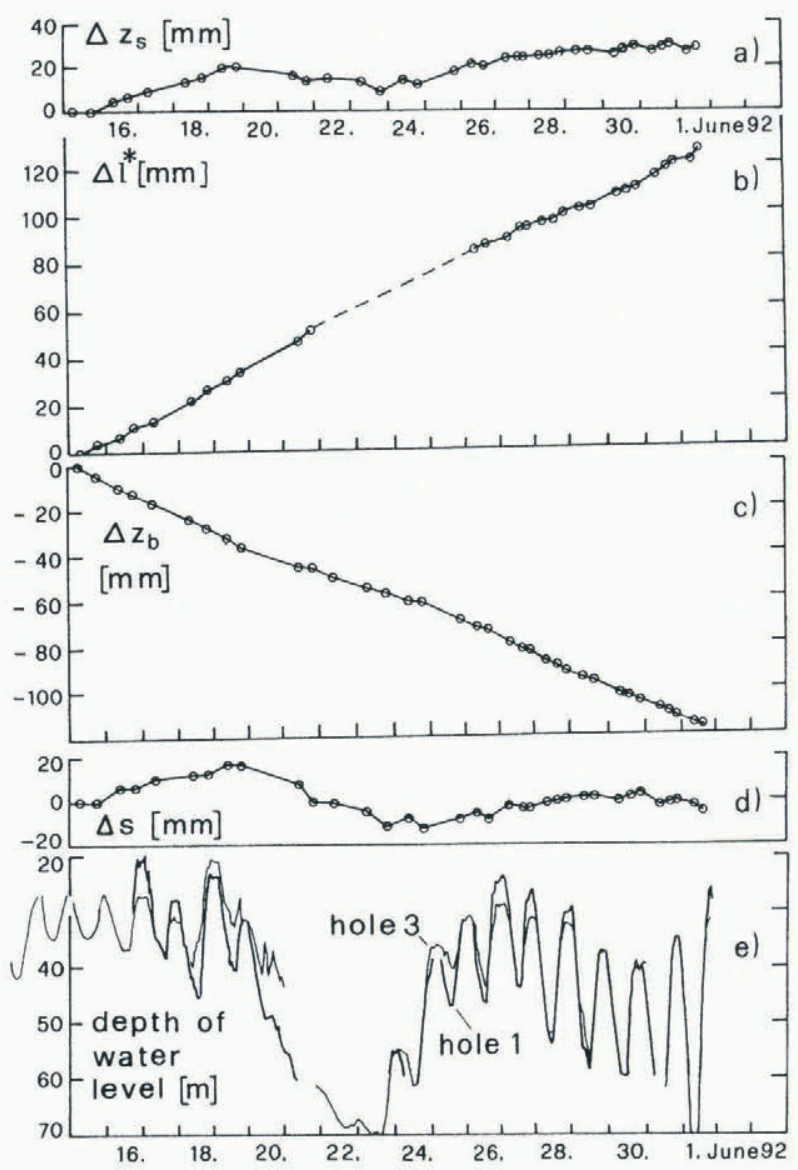

Fig. 3. Variations in vertical displacement at the surface, subglacial water storage and related quantities at site A, 1992. (a) Cumulative vertical displacement of pole $M$, $\Delta z_{\mathrm{s}}$. (b) Cumulative change in length of the borehole, betweeen a magnetic ring and pole $M$. The magnetic ring was anchored $10 \mathrm{~m}$ above the bed. (c) Inferred vertical component of sliding motion, assuming a bed slope of $-7^{\circ}$ (downhill) in sliding direction (Appendix A). (d) Inferred change in subglacial water storage, $\Delta s$. (e) Variations in water level in two boreholes. Hole 3 was located very close to pole $M$ (Fig. Ib).

$\pm 1 \mathrm{~mm}$ or less; an enlarged graph showing the tolerances is presented in Appendix A. Horizontal velocity is shown in Figure 4.

The vertical displacement, $\Delta z_{\mathrm{s}}$, of the reference mark on the surface, during time $\Delta t$, consists of the change in thickness of the glacier by strain, $\Delta d$, the vertical component of the sliding motion (as it would occur without water storage), $\Delta z_{\mathrm{b}}$, and of subglacial water

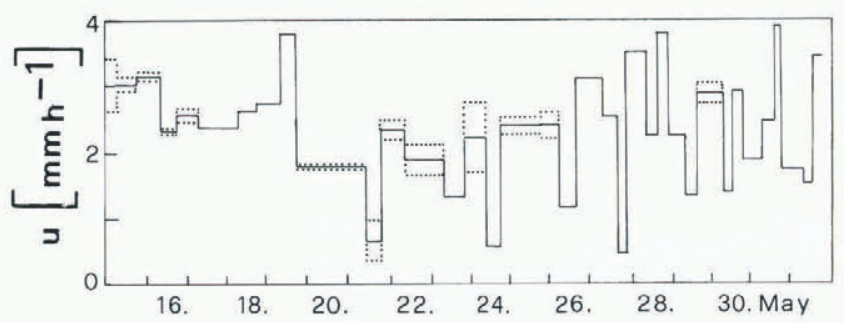

Fig. 4. Horizontal component of velocity of pole $M$. Dotted lines indicate tolerances, calculated from repeated readings when available. storage, $\Delta s$ :

$$
\Delta z_{\mathrm{s}}=\Delta d+\Delta z_{\mathrm{b}}+\Delta s .
$$

$\Delta d$ can be equated with the change in length of the borehole, $\Delta l^{*}$ (Fig. $3 \mathrm{~b}$ ), because curvature and tilt of the hole remained negligible during the 2.5 weeks of measurements. $\Delta z_{\mathrm{b}}$ is given by

$$
\Delta z_{\mathrm{b}}=\left(u_{\mathrm{s}}-u_{\mathrm{d}}\right) \Delta t \tan \beta
$$

where $u_{\mathrm{d}}$ is the deformational contribution to $u_{\mathrm{s}}$, the horizontal velocity at the surface, $\Delta t$ is a time interval between measurements and $\tan \beta$ is the slope of the bed in sliding direction (a mean value over a distance large enough to influence the direction of movement at the height of the magnetic ring).

Changes in bed elevation along the sliding path, $\Delta z_{\mathrm{b}}$, have been inferred from Equation (2), with $u_{\mathrm{d}}=$ $0.44 \mathrm{~mm} \mathrm{~h}^{-1}$ and $\beta=-7^{\circ}$; the choice of the numerical values of $u_{\mathrm{d}}$ and $\beta$ is discussed in Appendix A. Cumulative changes of $\Delta z_{\mathrm{b}}$ are shown in Figure 3c. Finally, changes in subglacial water storage have been inferred from Equation (1); they are plotted in Figure 3d.

The variations in water storage are similar to those in elevation of the reference pole (Fig. 3a). Moreover, they are related to the variations in subglacial water pressure, depicted in Figure 3e as variations in depth of water levels in boreholes. During a period of cold weather and snowfalls, 20-23 May, the water levels dropped by some $40 \mathrm{~m}$. With a delay of about $1 \mathrm{~d}$, water storage was also diminished; the release from storage was equivalent to a layer of $25-30 \mathrm{~mm}$ thickness. The water pressure rose again from 23 to 27 May; storage increased from 24 to 29 May. This demonstrates that the type of subglacial water storage considered here is slower than storage in boreholes or moulins. The small diurnal cycle of water storage, noticeable on 30 and $31 \mathrm{May}$, is within tolerances, but may well be real.

In summary: In the period of observations the changes in subglacial water storage amounted to about $25 \mathrm{~mm}$; they were the main cause of similar variations in elevation of the reference pole. Subglacial water storage or release was a slow process, driven by variations in subglacial water pressure but responding with a time lag.

Comparison of the present results with earlier findings on uplift raises two questions. Why was the recorded variation in water storage much smaller in 1992 $(\approx 25 \mathrm{~mm})$ than in $1979(\approx 100 \mathrm{~mm})$ ? And how can the differences in time lag be understood? The present investigation demonstrates a close correspondence of variations in water pressure and storage, with time lags of only about $1 \mathrm{~d}$. In contrast, the uplift observed in 1979 was not followed by a comparable release within the next two or three days (thereafter measurements were discontinued). Similarly, the uplift of Unteraargletscher, interpreted as water storage (Iken and others, 1983), was to a large extent preserved till autumn, except for very high rates of upward velocity which were followed by phases of downward velocity within a few days.

The likely answer to the first of these questions follows from the reduced dynamics of Gornergletscher: this glacier has thinned considerably since 1979 (about $30 \mathrm{~m}$ 
in the investigated area), and the velocity measured in spring 1992 was only about $50 \%$ of that in 1979. The large-scale variations in water storage encountered here are most likely variations in the size of subglacial cavities created by the sliding motion. This explanation is, of course, not unequivocal, in view of the experimental problem mentioned above. Moreover, the possibility of uphill sliding at $\mathrm{P}_{2}$ but not at $\mathrm{M}$ cannot be completely dismissed. (If, however, a substantial uphill slope were present at $\mathrm{P}_{2}$, short-term variations in horizontal velocity would cause noticeable variations in the rate of vertical displacement; this is not the case.)

Differences in time lag or duration of storage are probably a consequence of different drainage conditions of the storage spaces. In area A the drainage system was very efficient, frictional losses along subglacial drainage courses being quite small (see below). In contrast, drainage from boreholes in area B was impeded. Difficulties had also been encountered near $\mathrm{P}_{3}$ (in 1979) in attempting to drill holes which became connected with the subglacial drainage system.

\section{ELEGTRODE TESTS}

Two types of electrode tests were carried out. In the first type of tests, one electrode is brought into contact with rock at the glacier margin, and the other is lowered into the borehole while the current is measured. This method has been described in detail by Haeberli and Fisch (1984). The circuit is sketched in the inset of Figure 5. In our experiment, the voltage source was a $300 \mathrm{~V}$ dry battery,

At site $\mathrm{A}$ the current remained low until the second

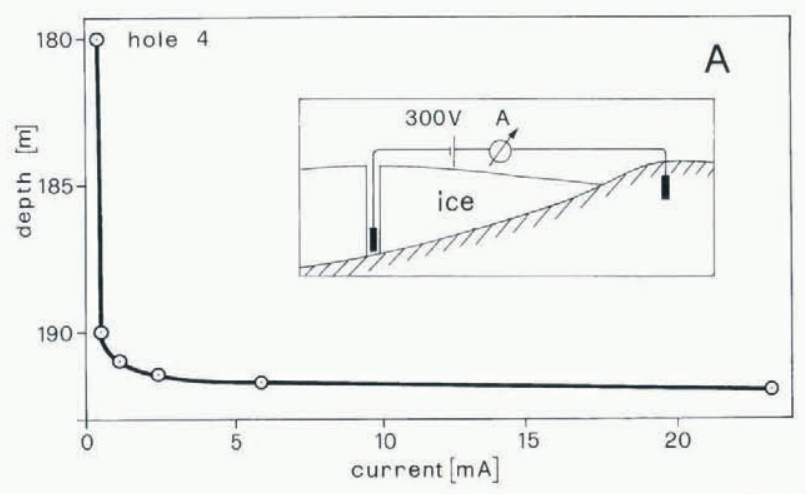

Fig. 5. Electrode test in a borehole at site A: current as a function of depth. When the borehole electrode approached the bed, the current increased by an order of magnitude. The insert is a sketch of the circuit.

electrode nearly touched the bed. Within the last meter, the current increased by an order of magnitude (Fig. 5). At site $\mathrm{B}$ the current started to increase well above the bed, but the increase of current at the bed was relatively less marked (Fig. 6). The records shown in Figures 5 and 6 are representative for all holes at sites $\mathrm{A}$ and $\mathrm{B}$, respectively.

We attribute the difference in change of current near the bed at sites $\mathrm{A}$ and $\mathrm{B}$ to a difference in debris content of

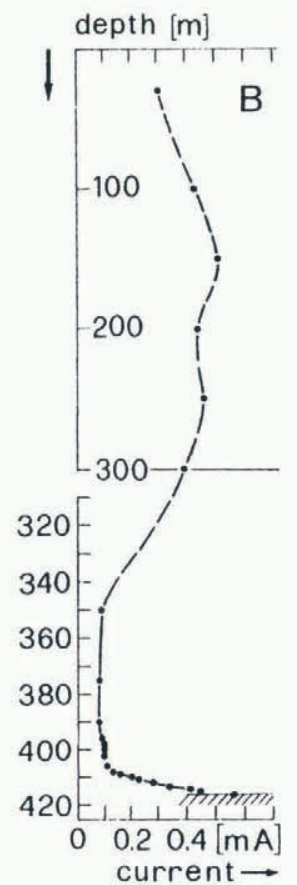

Fig. 6. Electrode test in a borehole at site B. When the borehole electrode approached the bed, the increase in current was much more gradual than at sile $A$. Note the change in scale on the vertical axis. Scales differ from those in Figure 5.

the basal ice. This presumption agrees with the drilling experience. When the drill stem was recovered from holes at site $\mathrm{A}$, it showed no scratches, but at site $\mathrm{B}$ it became scratched and ground. Moreover, at certain depths the drilling speed was reduced, presumably when the drill passed debris-containing ice layers. When the drill reached its final depth in holes at site $B$, the holes drained very slowly. We suspect that the drill penetrated a debris layer, one or a few decimeters thick, before it reached bedrock. In contrast, holes at site A drained very quickly, presumably through a linked-cavity system on "clean" bedrock. The abrupt change in current here indicates a sharp boundary at the bed.

There is one problem with this interpretation. In general, one would expect a debris layer at the bed of a sliding glacier to be a better electrical conductor than "clean" bedrock (site A), because of relatively mobile ions contained in the water-saturated debris. This expectation is not borne out by the measured currents (Figs 5 and 6). The reason may be that ions became washed out of the sediment layers by the clean water gushing from the drill; the electrode tests were carried out immediately after drilling.

The second type of electrode tests were measurements of electrical conductivity of the water at the bottom of boreholes. This experiment was performed at site A only. $1 \mathrm{kHz}$ voltage sources were connected with simple twoconductor electrode pairs (platinum), which had been calibrated in salt solutions of different concentrations at $0^{\circ} \mathrm{C}$. These electrode pairs were installed at the bottoms of boreholes 5-7 (Fig. 1b). At 1515 h on 18 May a solution containing $4 \mathrm{~kg}$ of sodium chloride was pumped through the drill hose to the bottom of hole 3. (This and the other holes at site A had drained immediately after drilling; 
durable connections had been established with the subglacial drainage system.) After one hour, $0.4 \mathrm{~m}^{3}$ of clean water was pumped into hole 3 . As soon as the salt solution had been injected, the electrical conductivity was measured in holes 5-7. No noticeable quantity of surface meltwater was flowing into the holes. Readings were taken continuously for $4 \mathrm{~h}$ and sporadically thereafter, but no sign of an arrival of the salt solution at one of the holes was recorded. A possible explanation is that the salt solution was routed through discrete subglacial drainage courses which did not pass along any of the boreholes. This explanation agrees with a conclusion drawn from the first type of tests.

The electrical conductivity measured in holes fluctuated in an irregular way between 35 and $80 \mu \mathrm{S} \mathrm{cm}^{-1}$. During the experiment the water pressure was rising, which ensures that the measured conductivity refers to undiluted subglacial water. Incidentally, Collins (1979) estimated the electrical conductivity of "subglacial water" of Gornergletscher as $44 \mu \mathrm{S} \mathrm{cm}^{-1}$. Based on this value (which falls into the above range), Collins determined the contributions of "englacial" and "subglacial" flow to the total discharge of the outlet stream of Gornergletscher.

\section{SLUG TESTS}

Slug tests are a standard technique in hydrogeology, applied in the investigation of drainage conditions. In these tests the natural height of the water level in a borehole is perturbed. In the present study this was carried out in two ways. Either a cylinder was submerged in the water of the borehole and, after readjustment of the water level, pulled up quickly, or a water container was emptied into the hole. Especially in this latter, crude experiment, not only is a water quantity added, but also a strong impulse is transferred to the water column in the borehole. The subsequent oscillation and readjustment of the water level were observed by following the motion of the level with a float-switch, suspended from a cable. (More precise and continuous data could have been obtained with a suitable pressure transducer, not available at that time.)

\section{Observations near the glacier margin, site $\mathbf{A}$}

Here the slug tests induced an oscillation of the water level lasting several minutes. During some of the tests the natural height of the water level changed gradually or in an irregular way, superimposed on the oscillation (Fig. 7). The period of oscillation was in the range of $30-45 \mathrm{~s}$. The period decreased somewhat with time, i.e. the frequency increased (Fig. 8). The logarithmic decrement $\lambda$ was not constant but tended to decrease with time. $\lambda$ is defined as:

$$
\lambda=\ln \frac{a(t)}{a(t+T)}
$$

where $a(t)$ and $a(t+T)$ are two successive amplitudes of oscillations, at time $t$ and $t+T$. $T$ is the period.

Tests carried out by lifting the submerged cylinder had no effect in neighboring boreholes. In contrast, when

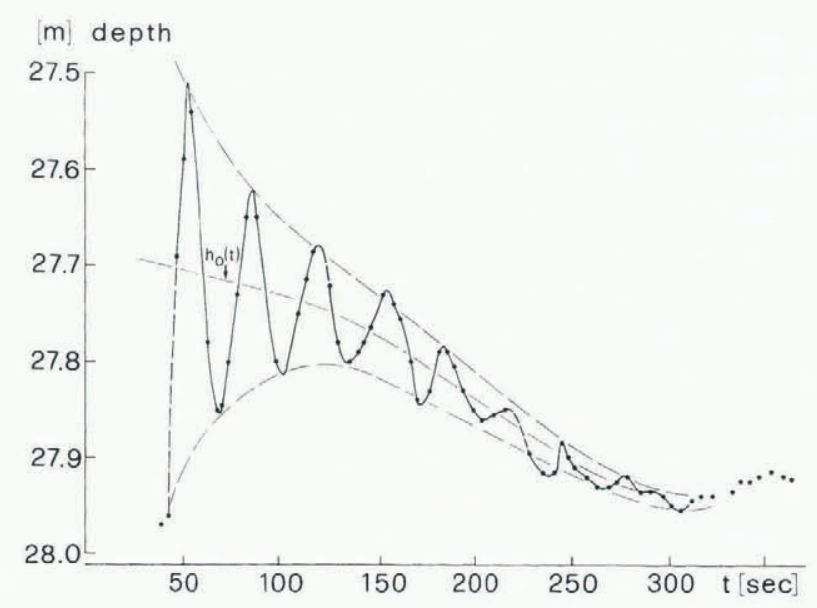

Fig. 7. Slug test in a borehole at site A; shown is the depth of water level vs time. The slug at time 0 induced an oscillation. Superimposed was a gradual change in the natural, unperturbed depth of water level, indicated by the line labeled $h_{0}(t)$ (19 May 1992, 2035h).

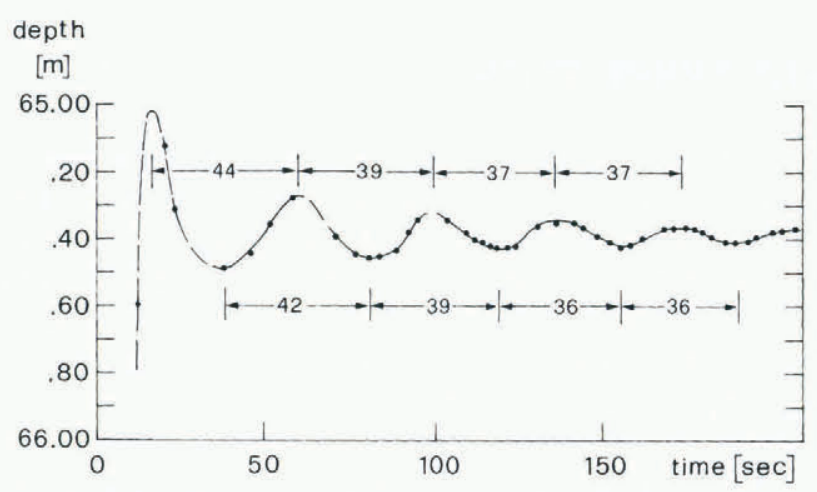

Fig. 8. Slug test at site A on 23 May 1992, 1100h. A slight decrease in the period of the oscillation is noticeable.

a cask with $100 \mathrm{l}$ of water was emptied into one borehole, a slight oscillation of different frequency was induced in the nearest boreholes to it, $17 \mathrm{~m}$ distant, but not in a hole at $23 \mathrm{~m}$ distance. After the initial impact, the oscillations in the two holes appeared to be independent of each other.

The observations are summarized in Table 1 , together with some numerical results.

\section{Observations near the center line, site B}

In this area the drainage conditions were quite different. The first two holes, drilled at a distance of $8 \mathrm{~m}$ from each other, drained very slowly and the level did not quite reach the depth corresponding here to overburden pressure. A third hole was drilled some $40 \mathrm{~m}$ northeast of the first two holes, further away from the center of the overdeepening. An attempt was made to improve drainage conditions in this hole by enlarging its bottom part to a diameter of approximately $0.5 \mathrm{~m}$ (estimate based on additional input of hot water). Here the water level dropped to a depth well below that corresponding to overburden pressure, but not nearly as deep as had been measured in a moulin at the medial moraine in July 1974.

In the enlarged hole a few tests were carried out by 
pouring in 311 of water. An example is shown in Figure 9. A first part of the water input arrived at high velocity at the water level and induced a slight downward displacement of the latter. The main part of water input piled up in the hole; subsequently the surplus in water drained gradually.

Before analyzing these observations, we will focus on typical features of different types of oscillating systems, as they show up in simple models.

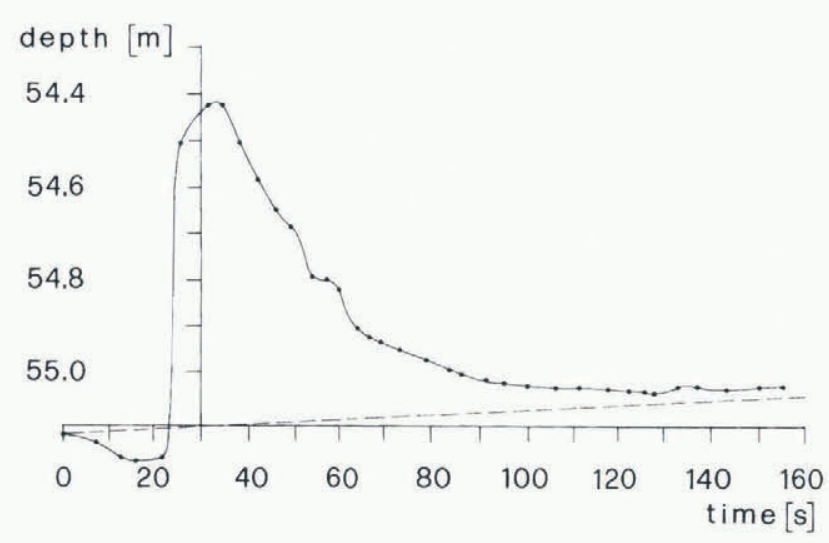

Fig. 9. Depth of water level during a crude slug test in the most pervious borehole at site $B$; a bucket of $31 \mathrm{l}$ of water was emptied into the hole. The broken line indicates the gradual, natural rise of water level during the experiment (25 June 1993, 1035h).

\section{MODELS OF OSCILLATING FLOW}

Various models will be considered which represent a variety of possible subglacial conditions in an idealized way. We start with a model of a single subglacial channel and subsequently generalize this situation. Stone and Clarke (1993) have taken a different approach; they develop a theoretical framework for the general case of radial flow.

A very simple oscillating system is sketched in Figure 10a. It consists of the water column in the borehole and a subglacial channel which connects the borehole with a very large reservoir. This reservoir illustrates the condition of constant pressure at location C (Fig. 10a), at the end of the subglacial channel. Alternatively, the condition of constant pressure could be realized by connecting the oscillating system with a subglacial stream of large discharge.

The equation of oscillation will be derived from a balance of forces acting on an element of unit cross-section and infinitesimal length, $\mathrm{d} s$, aligned in flow direction:

$$
-\frac{\partial p}{\partial s} \mathrm{~d} s+\rho g \sin \alpha \mathrm{d} s+\rho \frac{\mathrm{d} u}{\mathrm{~d} t} \mathrm{~d} s=0
$$

where $p$ is pressure (pressures, i.e. compressive stresses, are reckoned negative), $\rho$ is the density of water, $g$ $\left(=+9.81 \mathrm{~m} \mathrm{~s}^{-2}\right)$ is the (absolute value of) gravity, $\alpha$ is the angle between the horizontal and $\mathrm{d} s(\alpha$ is negative

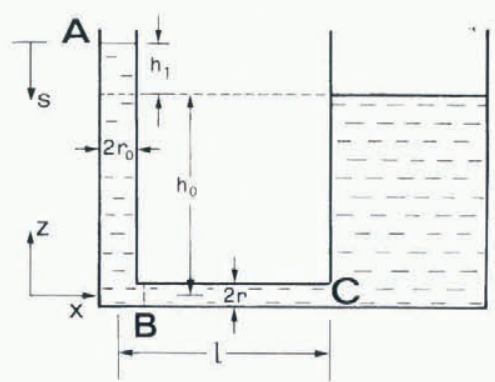

a

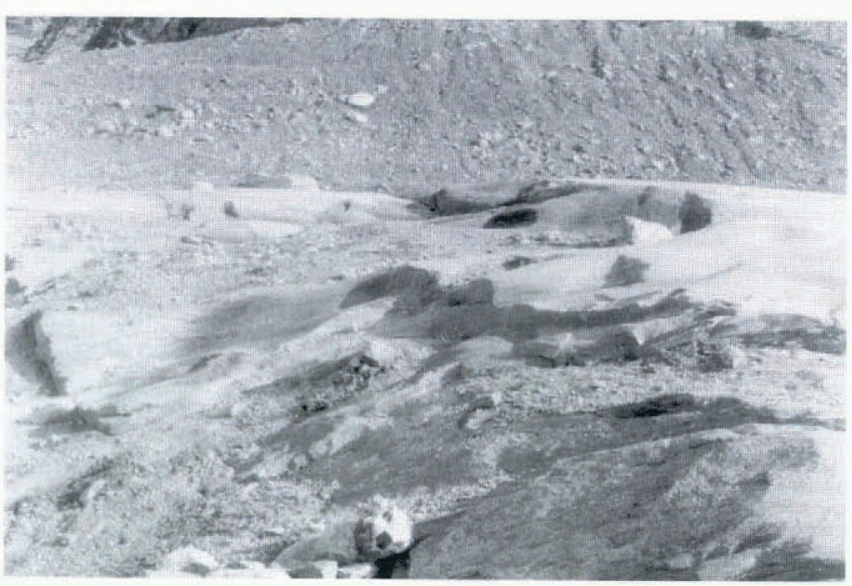

c

Fig. 10. (a) Simplified oscillating system. On the lefthand side, the lower part of a borehole is shown; it is filled with water up to point $A$. The natural, unperturbed height of water level is $h_{0}$. In the simple case, shown here, the borehole drains at the bed, at $B$, into one tube of radius $r$ connected with a large reservoir, symbolizing the condition of constant pressure at C. (b) A special case of branching of the subglacial conduit $B C$ : repeated branching at distances $\Delta l$ (constant). All branches are thought to have the same radius $r$. (c) Photograph of former, now exposed, glacier bed at northern margin, near $A$.

here because $\mathrm{d} s$ is directed downward), and $u(=\mathrm{d} s / \mathrm{d} t)$ is the velocity of the element.

The first term of Equation (4) represents the net force resulting from the difference in pressure acting on the front and rear surface of the considered element. The second term is the component of the weight of the element in direction $\mathrm{d} s$. The third term represents the change in momentum. If the equation is expressed in terms of a coordinate system fixed in space (or in terms of fixed reference points), the third term is replaced according to Equation (4a):

$$
\rho \frac{\mathrm{d} u}{\mathrm{~d} t} \mathrm{~d} s=\rho\left(\frac{\partial u}{\partial t} \mathrm{~d} s+\frac{\partial u}{\partial s} u \mathrm{~d} s\right) .
$$

Integration of Equation (4) with respect to $s$ yields an equation originally derived by D. Bernoulli (1700-82) and treated explicitly in textbooks of fluid dynamics (e.g. Hutter, 1991). We start with an integration between the limits $s=0$, at $\mathrm{A}$, and $s=h_{1}+h_{0}$, at $\mathrm{B}$, where $\mathrm{A}$ and $\mathrm{B}$ are fixed in space (Fig. 10a): 


$$
\begin{aligned}
& -p(B)+p(A)-\rho g\left(h_{1}+h_{0}\right)+\rho\left(h_{1}+h_{0}\right) \frac{\partial u(A)}{\partial t} \\
& +\frac{\rho}{2}\left\{[u(B)]^{2}-[u(A)]^{2}\right\}=0
\end{aligned}
$$

where $h_{0}$ is the unperturbed height of the water column in the borehole, $h_{1}$ is the deviation from the unperturbed height (positive upward), $u(A)$ is the flow velocity in the borehole (positive downward), and $u(B)$ is the flow velocity in the subglacial conduit, related to $u(A)$ by continuity:

$$
u(B)=u(A) \frac{r_{0}^{2}}{r^{2}} .
$$

These velocities may also be expressed in terms of $\dot{h}_{1}$, the time derivative of $h_{1}$ :

$$
u(A)=-\dot{h_{1}}, \quad u(B)=-\dot{h}_{1} \frac{r_{0}^{2}}{r^{2}} .
$$

Integration of Equation (4) between the limits B and C results in:

$$
-p(C)+p(B)+\rho l \frac{\partial u(B)}{\partial t}+\frac{\rho}{2}\left\{[u(C)]^{2}-[u(B)]^{2}\right\}=0 .
$$

So far, no allowance has been made for friction along the walls of the ducts. In the smooth borehole, some $10 \mathrm{~cm}$ in diameter, friction is negligible. In the subglacial conduit, however, friction is to be accounted for by adding a term $\left(\operatorname{sgn} \dot{h}_{1}\right)\left|\Delta p_{\mathrm{F}}\right|$ to Equation (7). The dependency of $\left|\Delta p_{\mathrm{F}}\right|$ on various parameters and on the type of flow will be discussed below. Introducing $\left(\operatorname{sgn} \dot{h}_{1}\right)\left|\Delta p_{\mathrm{F}}\right|$ into Equation (7) and observing that $u(C)=0$, we get:

$$
-p(C)+p(B)+\rho l \frac{\partial u(B)}{\partial t}-\frac{\rho}{2}[u(B)]^{2}-\left(\operatorname{sgn} \dot{h}_{1}\right)\left|\Delta p_{\mathrm{F}}\right|=0 .
$$

Adding Equations (5) and (7a) and expressing $u(A)$ and $u(B)$ in terms of $\dot{h}_{1}$ (by Equation $(6 a)$ ) yields

$$
\begin{gathered}
p(A)-p(C)-\rho g\left(h_{1}+h_{0}\right)-\rho \frac{\partial \dot{h_{1}}}{\partial t}\left(h_{1}+h_{0}+l \frac{r_{0}{ }^{2}}{r^{2}}\right) \\
-\frac{\rho}{2} \dot{h}_{1}{ }^{2}-\left(\operatorname{sgn} \dot{h}_{1}\right)\left|\Delta p_{\mathrm{F}}\right|=0 .
\end{gathered}
$$

The length $l$ of the subglacial conduit appears in Equation (8) with a weighting factor $r_{0}^{2} / r^{2}$, the ratio of the cross-sections of the borehole and of the subglacial channel. This is a consequence of the continuity condition (Equation (6)). By an analogous argument, each section $\mathrm{d} x$ of a subglacial oscillating system of variable crosssection $A(x)$ is weighted with a factor $\pi r_{0}^{2} / A(x)$, and hence the total weighted length of the subglacial system is

$$
L=\int_{0}^{1} \frac{\pi r_{0}^{2}}{A(x)} \mathrm{d} x .
$$

Equation (8) may thus be generalized by replacing $l r_{0}{ }^{2} / r^{2}$ with $L$. In addition, we insert $p(A)=0$ and
$p(C)=-\rho g h_{0}$. Atmospheric pressure need not be accounted for, because it has access to the subglacial drainage system at the terminus and elsewhere.) The equation may be linearized by neglecting $h_{1}$ in the expression for the total length of the oscillating system and by neglecting the small term $(\rho / 2) / \dot{h}_{1}{ }^{2}$. With these alterations and after division by $\rho\left(h_{0}+L\right)$ we finally obtain

$$
\frac{\partial \dot{h_{1}}}{\partial t}+\frac{g h_{1}}{h_{0}+L}+\frac{\left(\operatorname{sgn} \dot{h}_{1}\right)\left|\Delta p_{\mathrm{F}(\text { channel })}\right|}{\rho\left(h_{0}+L\right)}=0 .
$$

This equation is linear if $\Delta p_{\mathrm{F}}$ is linear in $\dot{h_{1}}$, i.e. in case of laminar flow; in this case, there is a solution

$$
h_{1}=h_{1(\max )} \mathrm{e}^{-\frac{1 \chi}{2 m} t} \cos \left(\sqrt{\frac{D}{m}-\frac{\chi^{2}}{4 m^{2}} t}\right)
$$

where

$$
\begin{aligned}
m & =\rho\left(h_{0}+L\right), \\
\chi & =\left|\Delta p_{\mathrm{f}} / \dot{h}_{1}\right|, \text { and } \\
D & =\rho g .
\end{aligned}
$$

The frequency

$$
\omega=\sqrt{\frac{D}{m}-\frac{\chi^{2}}{4 m^{2}}}
$$

decreases with increasing friction, and oscillations are suppressed if

$$
\left(\frac{\chi}{2 m}\right)^{2} \geq \frac{D}{m}
$$

In the case of laminar flow considered here, $\omega$ does not change with time, in contrast to oscillations in turbulent flow where the frictional term is proportional to $\dot{h}_{1}{ }^{2}$.

In that case, the frequency increases with time and eventually approaches the undamped frequency, as can be expected if one writes the frictional term of turbulent flow as

$$
\left|\Delta p_{\mathrm{F}}\right|=\hat{\chi} \dot{h}_{1}^{2}=\left(\hat{\chi} \dot{h}_{1}\right) \dot{h_{1}}
$$

Here the absolute value of the bracket on the righthand side decreases with time.

The frequency of the undamped oscillation, $\omega_{0}$, follows from Equation (11) with $\chi=0$ :

$$
\omega_{0}=\sqrt{\frac{D}{m}}=\sqrt{\frac{g}{h_{0}+L}}=\sqrt{\frac{g}{h_{0}+\int_{0}^{1} \frac{\pi r_{0}^{2}}{A(x)} \mathrm{d} x}} .
$$

Equation (11a) will now be used to calculate the frequency of the following undamped oscillating systems: (a) flow into a system of branching subglacial channels, and (b) radial flow.

(a) The subglacial channel branches at a distance $\Delta l$ from the borehole, so that there are then two channels, each of cross-section $\pi r^{2}$. These channels branch again after another distance $\Delta l$ and so on, as sketched in Figure 10b. The very frequent branching implies that the flow velocity is negligible at a distance of a few $\Delta l$ 
from the borehole, i.e., the water has arrived in the "very large reservoir of constant pressure".

This system has an undamped frequency

$$
\begin{aligned}
\omega_{0, \mathrm{a}} & =\sqrt{\frac{g}{\left(h_{0}+L\right)}} \text { with } \\
L & =\lim n \rightarrow \infty \Delta l \frac{r_{0}^{2}}{r^{2}} \sum_{i=0}^{n} 2^{-i}=2 \Delta l \frac{r_{0}^{2}}{r^{2}} .
\end{aligned}
$$

(b) Water flows radially from the borehole, either into a sediment layer beneath the glacier or into a narrow gap between glacier sole and bedrock with interspersed contact zones which limit water flow to a fraction $F$ of the glacier bed. Similarly, the kinematic porosity $n_{\mathrm{k}}$ ((volume of circulating water)/(total volume of sediment)) of the sediment layer is a measure of the cross-section of water flow through the sediment. If the gap, or sediment layer, has a thickness $b$, the cross-section of flow at a distance $R$ is

$$
A(R)=2 R \pi b F \quad(\text { gap })
$$

or

$$
A(R)=2 R \pi b n_{\mathrm{k}} \quad \text { (sediment). }
$$

Inserting $A(R)$ from Equation (13a) for $A(x)$ into Equation (11a), we obtain an approximate expression for the undamped frequency:

$$
\begin{aligned}
\omega_{0, \mathrm{~b}} & \approx \sqrt{\frac{g}{\left(h_{0}+\int_{r_{0}}^{R_{l}} \frac{\pi r_{0}^{2}}{2 R \pi b F} \mathrm{~d} R\right)}} \\
& =\sqrt{\frac{g}{\left(h_{0}+\frac{r_{0}^{2}}{2 b F} \ln \frac{R_{l}}{r_{0}}\right)}} .
\end{aligned}
$$

Here, $R_{l}$ is the distance from the borehole where the water pressure remains constant.

In the case of a sediment layer, $F$ in Equation (14) is replaced by $n_{\mathrm{k}}$. Equation (14) slightly overestimates the undamped frequency, because the subglacial flow is not strictly in radial direction but follows a winding path around grains or contact areas.

The conditions for various types of damping are briefly surveyed in Appendix B.

\section{SHORT-TERM STORAGE DURING SLUG TESTS}

If the tested borehole has efficient connections with other boreholes or nearby moulins, storage will occur in these pipes, and a system of coupled oscillations will function. This situation was not encountered in the experiments at Gornergletscher. Other possible storage spaces are basal water films, linked-cavity systems or basal sediment layers. For the short duration of slug tests these storage spaces adjust their volume essentially elastically. The elastic compressibilities of water $\left(\beta_{1} \approx 5 \times 10^{-10} \mathrm{~Pa}^{-1}\right)$ and of rocks or grains (e.g. quartz, $\beta_{\mathrm{s}} \approx 2 \times 10^{-11} \mathrm{~Pa}^{-1}$ ) are, however, quite small and can in general be neglected. More important are storage changes which are due to changes of shape: (a) Elastic storage changes in subglacial water sheets or interconnected cavities can be estimated by assuming that the change in water pressure affects a circular area of the glacier sole with radius $R_{\mathrm{s}}$. The maximum deflection, $\Delta D$, in the center is then

$$
\Delta D=\frac{2(1-\nu)^{2} R_{\mathrm{s}}}{E} \Delta p
$$

(Timoshenko and Goodier, 1982, p. 403). Here $\nu \approx 0.33$ is Poisson's ratio, and $E \approx 9.6 \times 10^{9} \mathrm{~Pa}$ is the elastic modulus of ice. The corresponding volume change $\Delta V$ is approximately

$$
\Delta V \approx \frac{1}{2} \Delta D R_{\mathrm{s}}^{2} \pi=\frac{(1-\nu)^{2} \pi R_{\mathrm{s}}^{3}}{E} \Delta p .
$$

For example, the volume change of a cavity with a radius of $1 \mathrm{~m}$ amounts to $1.5 \mathrm{~cm}^{3}$ if the water pressure changes by 0.1 bar $\left(10^{4} \mathrm{~Pa}\right)$ or, equivalently, if the water level changes by approximately $1 \mathrm{~m}$. This shows that elastic storage during slug tests is very small in common linked-cavity systems, but can play a role in "sheets" of large lateral extent. In slug-test oscillations, elastic storage would tend to make the maxima sharper and the minima blunter.

(b) In a sediment layer a change of pore pressure causes a change in contact stress between grains and a change in shape of the grains. With increasing pore pressure the grains assume a more rounded shape which is accompanied by a growth of pores. The corresponding volume change of the sediment layer, neglecting the compressibility of water and of the grains, is given by

$$
\frac{\Delta V}{V}=\alpha \Delta p
$$

where $\Delta p$ is the change in pore pressure, and $\alpha$ is the compressibility of the porous substance. For sand, for example, $\alpha$ is in the range $10^{7}$ to $10^{9} \mathrm{~Pa}^{-1}$, and is thus one to three orders of magnitude larger than the compressibility of water. Storage changes induced by slug tests would still be very small. However, in combination with a low permeability of the sediment and correspondingly small seepage velocity, this type of storage can alter the recovery curve. We will return to this point in the next section.

\section{INTERPRETATION OF SLUG TESTS}

\section{Site A}

Some insight follows immediately from the observations. The increase of frequency with time, as well as the variability of the logarithmic decrement (Equation (10)), suggests that the oscillating flow was not laminar but, at least in part, turbulent. The observation that slug tests in one borehole were in general not felt in the others may point to discrete subglacial drainage paths. Further information can be drawn from the observed frequency. After the first two or three oscillations the frequency stayed approximately constant, and presumably approached the undamped frequency, $\omega_{0}$. Numerical 
modelling (Appendix C; Table 1) supports this presumption. By equating the measured frequency with the undamped one, the "weighted length" of the subglacial part of the oscillating system can be inferred from Equation (11a). In Table 1 the results of this calculation, values of

$$
L=\int_{0}^{1} \frac{r_{0}^{2} \pi}{A(x)} \mathrm{d} x,
$$

are listed, together with the length of the water column in the borehole, $h_{0}$, and the frequencies. Obviously, the values of $L$ are substantial; they amount to about $100 \mathrm{~m}$. For this reason, drainage through a sediment layer with a thickness $b \geq 0.1 \mathrm{~m}$ can be excluded as a possible subglacial drainage system at this test site. To see this, we evaluate the second summand of the denominator in Equation (14), where $F$ is replaced by $n_{\mathrm{k}}$ :

$$
L=\frac{r_{0}^{2}}{2 b n_{\mathrm{k}}} \ln \left(\frac{R_{1}}{r_{0}}\right) .
$$

For example, we assume a kinematic porosity $n_{\mathrm{k}}=0.3$, a borehole radius $r_{0}=0.05 \mathrm{~m}, b=0.1 \mathrm{~m}$, constant pressure at a distance $R_{l}=100 \mathrm{~m}$. With these values we obtain $L=0.3 \mathrm{~m}$, a far too small quantity. The result is insensitive to the choice of $R_{l}$. On the other hand, the possibility of drainage through a thin water film with a thickness $b \leq 1 \mathrm{~mm}$ cannot be excluded on these grounds. In this case, however, damping would likely prevent any oscillations. For illustration, we consider the case where the maximum rate of flow from the borehole is $Q=0.001 \mathrm{~m}^{3} \mathrm{~s}^{-1}$, the borehole radius near the bed is $R_{\mathrm{F}}=r_{0}=0.05 \mathrm{~m}$, the film thickness is $b=1 \mathrm{~mm}$, the roughness $R_{\mathrm{r}}=0.1$ and the fraction of the glacier sole not in contact with the bed is $F=0.5$. At a distance $R=0.1 \mathrm{~m}$ from the borehole the Reynolds number is $\mathrm{Re} \approx 3200$ (by Equation (B 1 1)) which indicates turbulent flow. The head required to drive the flow through the film is therefore calculated from Equation (B12), and amounts in this example to $3.6 \mathrm{~m}$. In the actual tests, however, the frictional loss of head was definitely smaller. (The assumed discharge of $Q=0.001 \mathrm{~m}^{3} \mathrm{~s}^{-1}$ corresponds to the maximum velocity observed shortly after triggering the oscillations (e.g. Fig. 7). At that stage the maximum amplitude was only about $0.2 \mathrm{~m}$.) Another reason for rejecting the hypothesis of flow through a thin film of large lateral extent follows from the absence of typical features of elastic storage in the records of oscillations: maxima and minima have a similar shape (Figs 7 and 8 ).

The slug tests indicate that subglacial drainage near the glacier margin was not accomplished as sheet flow or flow through sediments. On the contrary, subglacial drainage must have taken place along discrete paths, either through a linked-cavity network or through branching conduits. This result agrees with a preliminary conclusion drawn from the conductivity experiments. The appearance of the former glacier bed (Fig. 10c), the observed type of water storage and the absence of debris in the basal ice all point to the same conclusion. The subglacial passageways must have been numerous, since all boreholes drained immediately.

Another interesting fact is revealed by comparing the weighted length $L$ of the subglacial drainage system with long-term subglacial water storage, $\Delta s$. There is a distinct trend of decreasing $L$ with increasing storage (Table 1). Primarily, this finding reflects the increase of cross-section $A(x)$ of the subglacial drainage system (Equation (9)) with increasing water storage. This is what one would expect in view of the interpretations given here. In principle, a decrease of $L$ may also be caused by a decrease of the length $l$ of the subglacial connection between the borehole and the location where the pressure is constant (Equation (9)). Such a variation of $l$ with varying water storage seems unlikely in case of a single channel connected with the borehole. On the other hand, in the model of a branching system, i.e. a linked-cavity system, it is conceivable that the typical length of branches, $\Delta l$ (Equation (12)), decreases as water storage increases and subglacial cavities and linking branches become more numerous.

Table 1. Measured and calculated quantities, related to oscillations in a borehole near glacier margin

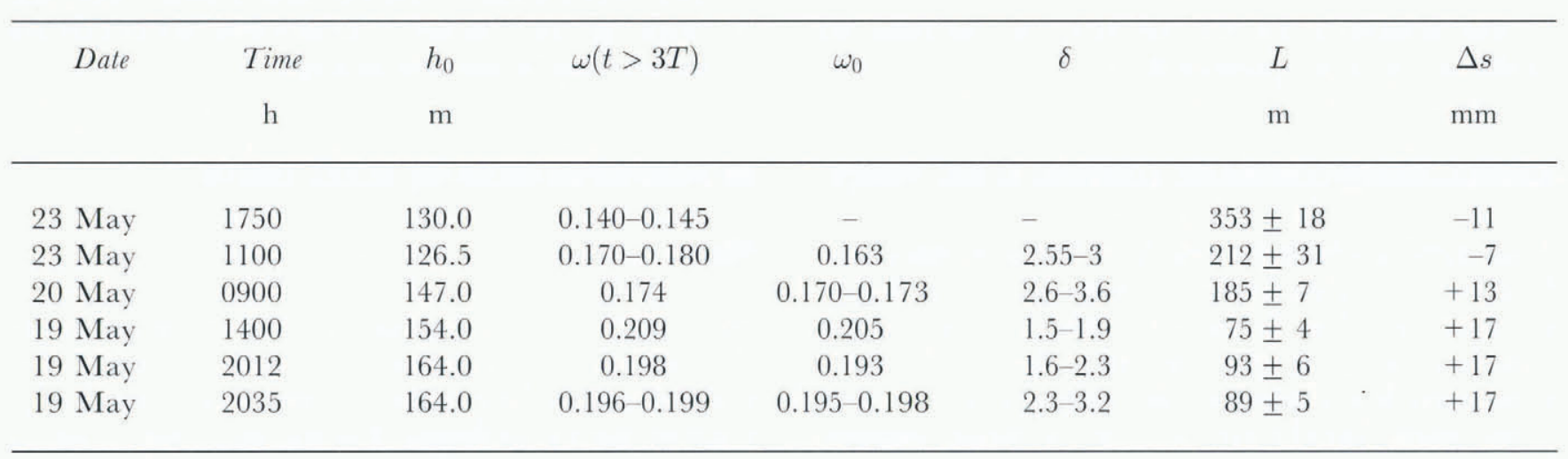

$h_{0}$, natural height of water column in borehole (total length of hole: $192 \mathrm{~m}$ ).

$\omega(t>3 T)$, frequency inferred directly from records, disregarding the first three oscillations.

$\omega_{0}$, undamped frequency determined by numerical method (Appendix C).

$\delta$, damping constant for turbulent flow, determined numerically. $\delta$ is defined by $\delta=\left|\Delta p_{\mathrm{F}}\right| /\left[\rho\left(h_{0}+L\right) \dot{h}_{1}{ }^{2}\right]$.

$L$, weighted length of subglacial part of oscillating system (Equation (9)).

$\Delta s$, change of subglacial water storage from datum (Fig. 3). 

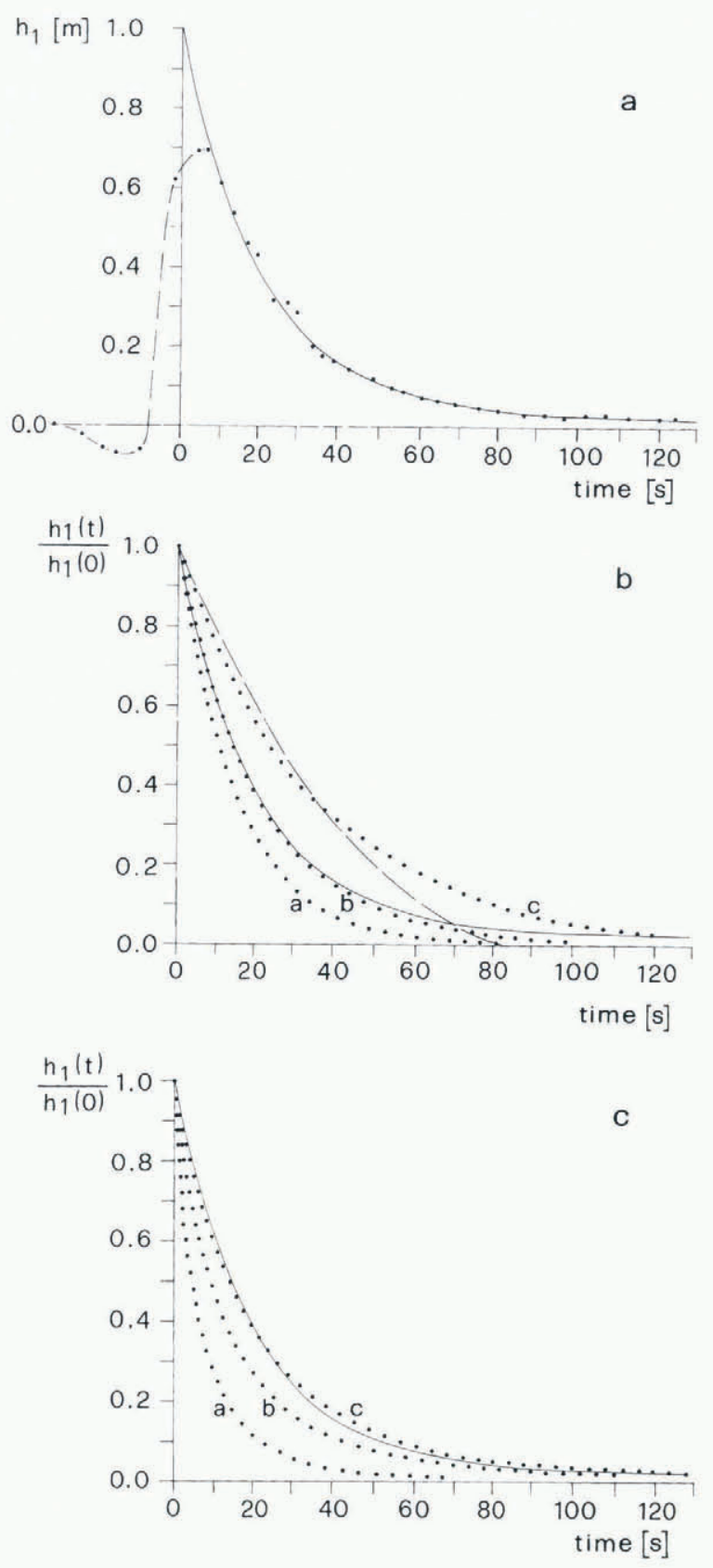

Fig. 11. Depletion curves for different types of drainage from a borehole. (a) Adjusted experimental depletion curve, based on data depicted in Figure 9 (slug test at site $B$ ). The gradual natural rise of the water level has been eliminated. The upper part of the solid line is an extrapolation, assuming that the total amount of pouredin water was added gently and instantaneously at the water surface in the hole. (b) Theoretical depletion curves for laminar flow (dotted lines) and turbulent flow (broken line) out of the borehole at its bottom. No storage. The different dotted lines refer to different initial velocities, $\dot{h} 1(o)$. Initial velocities have been chosen, so that an approximate fit with the adjusted experimental curve (thin solid line, as in (a)) was obtained. (c) Dotted lines depict radial laminar flow through uniform sediment layer of unlimited lateral extent. Storage by (elastic) change in pore volume of sediment is allowed for. The thickness of the sediment layer is here $b=0.1 \mathrm{~m}$. Curve $a: K=0.04$ $\mathrm{ms}^{-1} ; \gamma=10^{4}$. Curve $b: K=0.02 \mathrm{~ms}^{-1} ; \gamma=10^{-4}$. Curve c: $K=0.02 \mathrm{~ms}^{-1} ; \gamma=10^{-6}$. The thin solid line is the same as in $(a)$.

\section{Site B}

For a quantitative evaluation of the recovery curve (Fig. 9 ) it is necessary to correct for the gradual arrival of water at the water surface in the borehole and to compensate for the slight increase of the natural height of water level in the glacier which occurred during the experiment. The resulting depletion curve, which corresponds approximately to an instantaneous, gentle water addition of 311 at the water surface in the hole, is shown in Figure $11 \mathrm{a}$ and indicated by a thin solid line in Figure $11 \mathrm{~b}$ and $\mathrm{c}$.

In the following, this curve will be compared to theoretical predictions for different types of subglacial flow regimes. In view of the crudeness of the experiment and of the necessary adjustments, this analysis cannot describe the actual process exactly. However, it will make clear in what way the different drainage types affect the depletion curve.

Accelerations are negligible in the present experiment; hence, the pressure drop, $\Delta p_{\mathrm{F}}$, accounting for frictional energy dissipation is simply

$$
-\Delta p_{\mathrm{F}}=\rho g\left(h_{\mathrm{C}}-h_{\mathrm{B}}\right)=\rho g\left[h_{0}-\left(h_{1}+h_{0}\right)\right]=-\rho g h_{1} .
$$

Laminar flow in subglacial system draining the borehole In this case, the relationship between head and velocity (Equations (B2), (B4), (B9) and (B9a)) is linear; it is conveniently written as

$$
\frac{h_{1}(t)}{h_{1}(0)}=\frac{\dot{h_{1}}(t)}{\dot{h_{1}(0)}} .
$$

$h_{1}(0)$ and $\dot{h}_{1}(0)$ are the initial values of head and velocity, respectively. They refer to the instant $t=0$ when the water quantity is added to the water surface in the hole, and when the perturbation $h_{1}$ is at a maximum. Separation of variables and integration yields

$$
h_{1}(t)=h_{1}(0) \mathrm{e}^{-l \dot{h}_{1}(0) / h_{1}(0) l t} .
$$

This function is plotted for three reasonable values of $\dot{h}_{1}(0)$ (comparable to that in Figure 1la) with dotted lines in Figure $11 \mathrm{~b}$. (Different initial velocities correspond to different friction factors and geometries, as outlined in Appendix B.) The curve b in Figure $11 \mathrm{~b}$ agrees quite well with the "measured" curve for small $t$; for large $t$, however, the predicted deviations $h_{1}(t)$ are too small.

\section{Rough turbulence (Equations (B3), (B5) or (B7))}

If we assume that there was no subglacial flow in the vicinity of the borehole other than that induced by the slug experiment, we can write

$$
\frac{h_{1}(t)}{h_{1}(0)}=\frac{\left[\dot{h_{1}}(t)\right]^{2}}{\left[\dot{h_{1}}(0)\right]^{2}} \text {. }
$$

Integration of Equation (20) and rearrangement of terms results in

$$
\sqrt{h_{1}(t)}=\sqrt{h_{1}(0)}-\frac{1}{2} \frac{\dot{h}_{1}(0)}{\sqrt{h_{1}(0)}} t
$$


or

$$
h_{1}(t)=h_{1}(0)-\dot{h_{1}}(0) t+\frac{\left[\dot{h_{1}}(0)\right]^{2}}{4 h_{1}(0)} t^{2} .
$$

A graph of this function is shown in Figure $11 \mathrm{~b}$ with a broken line. Obviously, there is no agreement with the "measured" curve. It follows from Equation (21) that $h_{1}(t)$ becomes zero after the finite time $t_{\mathrm{f}}=2\left(h_{1}(0) /\right.$ $\dot{h}_{1}(0)$, in contrast to what was observed.

\section{Laminar flow with elastic storage}

As outlined above, elastic storage may be influential if drainage occurs through a sediment layer or, at high water pressure, through an extended sheet between glacier sole and bed. The rate of storage per unit volume $\dot{s}$, is proportional to the rate of change in head, $h(R, t)$ :

$$
\dot{s}=\frac{\partial h}{\partial t} S_{\mathrm{s}}
$$

or, by continuity,

$$
\frac{\partial h}{\partial t}=+\frac{K}{S_{\mathrm{s}}}\left(\frac{\partial^{2} h}{\partial R^{2}}+\frac{1}{R} \frac{\partial h}{\partial R}\right) .
$$

Here $S_{\mathrm{s}}$ is the specific storativity, which is given by

$$
S_{\mathrm{s}}=\rho g \alpha
$$

if the compressibility of water and of the grains is neglected. $K$ is the hydraulic conductivity of the sediment.

Carslaw and Jaeger (1988, p. 342) provide an analytic solution of Equation (24), applying to borehole drainage into a uniform sediment layer of given thickness, $b$, and unlimited lateral extent:

$\frac{h_{1}(t)}{h_{1}(0)}=\frac{4 \gamma}{\pi^{2}} \int_{0}^{\infty} \frac{\exp \left[-K t u^{2} /\left(r_{\mathrm{F}}^{2} S_{\mathrm{s}}\right)\right]}{u F(u)} \mathrm{d} u$

where

$$
\begin{aligned}
\gamma & =\frac{2 S_{\mathrm{s}} b r_{\mathrm{F}}^{2}}{r_{0}^{2}}, \\
F(u) & =\left[u J_{0}(u)-\gamma J_{1}(u)\right]^{2}+\left[u Y_{0}(u)-\gamma Y_{1}(u)\right]^{2},
\end{aligned}
$$

$r_{0}$ is the borehole radius at the water surface, $r_{\mathrm{F}}$ is the borehole radius in the sediment layer ("filter" radius), and $J_{n}$ and $Y_{n}$ are Bessel functions of the first and second kind, respectively, and of order $n$.

Graphs of $h_{1}(t) / h_{1}(0)$ vs time, according to Equation (26) and for different values of $\gamma$ and $K$, are shown in Figure 12c with dotted lines. These curves differ from those referring to laminar flow without storage (Fig. 1lb) by a larger rate of decrease of $h_{1}(t)$, immediately after the initiation of the slug and by a smaller rate of decrease of $h_{1}(t)$ at a later stage. The reason is that, immediately after the slug, water flowing from the borehole is not only transferred through the sediment but also absorbed by storage. At a later stage, at lower pressure, water is released from storage and thus adds to the flow out of the hole.

There is a reasonable agreement between the measured and a calculated curve in Figure 11c, namely curve c. We thus conclude that the considered hole drained by laminar flow with storage. Solution (26) may be interpreted either as flow through a sediment layer or as flow through a thin but extended "sheet" with interspersed contact areas. On the basis of the present experiment alone, it is not possible to decide which of these models is appropriate. However, the electrode tests, the experiences during drilling and the moderate height of water pressure make the existence of a sediment layer seem more likely. Assuming a sediment layer of, say, $b=0.1 \mathrm{~m}$ thickness, Equation (26) or Figure 11c, curve c, suggests that $K=0.02 \mathrm{~m} \mathrm{~s}^{-1}$ and $\gamma$ $\approx 10^{-6}$ or, with $r_{0} / r_{\mathrm{F}}=1 / 5, S_{\mathrm{s}}=2 \times 10^{-7} \mathrm{~m}^{-1}$. Increasing $b$ by a factor $a$ would result in $K^{*}=(1 / a) K$ and $\left.S_{\mathrm{s}}{ }^{*}=(1 / a) S_{\mathrm{s}}\right)$

The inferred hydraulic conductivity is quite large; it corresponds to that of coarse sand or gravel. On the other hand, the specific storativity, $S_{\mathrm{s}} \approx 10^{-7} \mathrm{~m}^{-1}$, is smaller than one would expect for subglacial sediments. This may indicate that an assumption of the analytic Solution (26) does not apply in the present case, the unlimited lateral extent of the sediment layer. Actually, the constant head, $h_{0}$, may be attained at a short distance from the borehole, e.g. if a large stream intersects the sediment layer. The evaluation done here, assuming an essentially unlimited extent of the sediment layer, would then result in too large a conductivity and too small a storativity, as is the case.

\section{GONGLUSION}

The combination of different borehole experiments has shown that two kinds of subglacial drainage systems are active beneath Gornergletscher.

Near the margin, at the upstream side of an overdeepening, drainage courses were discrete passageways, presumably linked cavities on clean bedrock, and were numerous and durable. Slug tests triggered long-lasting oscillations, in which part of the subglacial drainage system participated, with primarily turbulent flow. The oscillations were hardly noticeable in nearby boreholes, but the perviousness of the subglacial drainage system was evident in nearly equal water levels in different boreholes and in simultaneous diurnal variations.

During the period of field studies in May 1992, subglacial water storage changed by the equivalent of a $25 \mathrm{~mm}$ thick water layer. The variations in water storage were similar to variations in elevation of a pole, except that a steady rate of elevation change was superimposed on the latter. Storage changes were accomplished by changes in cross-section of the subglacial passageways (a slow process, like growth or shrinkage of subglacial cavities), which were evident in variations of the frequency of the slug-test oscillations. Storage changes corresponded to variations in subglacial water pressure with a time lag.

Near the center line, drainage of the boreholes was impeded. Slug tests (carried out in one borehole) caused no oscillations but were merely followed by a gradual recovery of the perturbation. Water flow from the 
borehole into the subglacial drainage system was laminar, with storage accomplished by elastic deformations. Probably the water flowed through a sediment layer, and water was stored in variable pore space. The abrupt stop of the drill advance, as well as the electrode tests, suggests that bedrock was reached and that the sediment layer between glacier sole and bedrock was thin. The latter conclusion is uncertain but, if it is correct, a certain amount of bed separation can be expected at boulders and bedrock humps sticking out of the sediments; bed separation plays a role in Collins' (1979) interpretation of his conductivity measurements. It would also provide an easy explanation of seasonal uplift which was similar to, but somewhat smaller than, that observed near the margin.

The picture emerging from these fragmentary observations and interpretations is of a poorly interconnected subglacial drainage system near the center line. Probably a few large drainage channels divert meltwater from moulins, and collect water from widespread sediment layers and temporarily shrinking cavities. Presumably this type of drainage system is more common beneath Gornergletscher than the wellinterconnected system near the margin; it is responsible for some typical features of the dynamics and hydrology of the glacier.

The few and simple tests described here have provided insight into the basal conditions of Gornergletscher. Slug tests, which require little effort, proved to be especially informative. Based on them alone, it was possible to exclude flow through films or seepage through sediments as relevant drainage types at the base of the glacier near the margin. The slug tests also suggested that large-scale subglacial water storage was accomplished by growth of cross-sections of cavity systems. More tests are desirable on the central part of the glacier: penetrometer tests, probing, analysis of uplift, improved slug tests and measurements of possible sediment deformation, for instance, as described by Fischer and Clarke (1994). A problem in the determination of subglacial water storage is posed by the poorly known inclination of the bed in sliding direction, a mean inclination over a not wellknown distance. An approximate value can be estimated by means of a sensitivity study and comparison with water pressure.

\section{ACKNOWLEDGEMENTS}

We wish to thank D. Vischer, director of VAW, for his interest in this study and very valuable advice. $\mathrm{H}$. Bösch, B. and H. Jenny, M. Lüthi, J. Luthiger, B. Nedela and C. Senn gave excellent assistance in the field. Special thanks are expressed to K. Schram for her great help in completing this paper. B. Nedela prepared the drawings and S. à Marca typed part of the manuscript. Logistic support was given by Swiss military helicopters and, in many ways, by the Grande Dixence SA. W. Haeberli, H. Röthlisberger, M. Truffer and D. Vonder Mühll read the manuscript and made valuable comments. We thank D. Stone for his thorough review and very constructive comments.

\section{REFERENCES}

Aschwanden, H. and C. Leibundgut. 1982. Die Markierung der Wasser des Gornerseeausbruches mit drei Fluoreszenztracern. Beitr. Geol. Schweiz., Ser. Hydrol., 28, 535-549.

Barna, P.S. 1969. Fluid mechanics for engineers. Third edition. Sydney, etc., Butterworth.

Bearth, P. 1953. Zermatt. In Geologischer Atlas der Schweiz 1: 25,000. Zürich, Schweizerische Geologische Kommission, Atlasblatt 29.

Carslaw, H.S. and J. C. Jaeger. 1988. Conduction of heal in solids. Second edition. Oxford. Clarendon Press.

Collins, D.N. 1979. Quantitative determination of the subglacial hydrology of two Alpine glaciers. 7. Glaciol., 23 89), 347-362.

Collins, D. N. 1989. Seasonal development of subglacial drainage and suspended sediment delivery to melt waters beneath an Alpine glacier. Ann. Glaciol., 13, 45-50.

Fischer, U.H. and G. K. C. Clarke, 1994. Ploughing of subglacial sediment. 7. Glaciol., 40 (134), 97-106.

Haeberli, W. and W. Fisch. 1984. Electrical resistivity soundings of glacier beds: a test study on Grubengletscher, Wallis, Swiss Alps. J. Glaciol., 30 106), 373-376.

Hutter, K. 1991. Einführung in die Fluid-und Thermodynamik. Darmstadt, Sclbstverlag.

Iken, A. 1978. Variations of surface velocities of some Alpine glaciers measured at intervals of a few hours: comparison with Arctic glaciers. Z. Gletscherkd. Glazialgeol., 13 1-2), 1977, $23-35$.

Iken, A., H. Röthlisberger, A. Flotron and W. Haeberli. 1983. The uplift of Unteraargletscher at the beginning of the melt season-a consequence of water storage at the bed? F. Glaciol., 29 (101), 28-47.

Marsily, G. de. 1986. Quantitative hydrogeology. San Diego, CA, Academic Press.

Röthlisberger, H. 1972. Water pressure in intra- and subglacial channels. J. Glaciol., $11(62), 177-203$.

Röthlisberger, H. 1980. Gletscherbewegung und Wasserabfluss. Wasser, Energie, Luft - Eau, Energie, Air, 72 9), 290-294.

Röthlisberger, H., A. Iken and U. Spring. 1979. Piezemetric observations of water pressure at the bed of Swiss glaciers. f. Glaciol., 23 89), 429430

Stone, D.B. and G. K. C. Clarke. 1993. Estimation of subglacial hydraulic properties from induced changes in basal water pressure: a theoretical framework for borehole-response tests. 7 . Glaciol., $39(132), 327-340$.

Timoshenko, S.P. and J. N. Goodier. 1982. Theory of elasticity. Third edition. New York, McGraw-Hill International Editions.

\section{APPENDIX A}

\section{TOLERANGES OF INFERRED CHANGES IN SUB- GLACIAL WATER STORAGE}

Numerical values of water storage, $\Delta s$, are inferred from measured changes in elevation of the reference pole, $\Delta z_{\mathrm{s}}$, and from changes in elevation of the magnetic ring, $\Delta z_{\mathrm{b}}$, by Equations (1) and (2). (For simplicity we disregard here the distance of $10 \mathrm{~m}$ between the magnetic ring and the glacier sole.

$$
\Delta s=\Delta z_{\mathrm{s}}-\Delta z_{\mathrm{b}}-\Delta d
$$

with

$$
\Delta z_{\mathrm{b}}=\left(u_{\mathrm{s}}-u_{\mathrm{d}}\right) \Delta t \tan \beta
$$

Standard deviations of $\Delta z_{\mathrm{s}}$, obtained from repeated readings of vertical angles, are shown as error bars in Figure 12. In general, these deviations are less than $\pm 1 \mathrm{~mm}$. Diurnal variations in vertical displacements displayed between 30 May and 1 June are probably real and not a result of diurnally varying refraction conditions. This is concluded from the absence of any diurnal variations between 15 and 19 May, a period with clear sky during which one might expect diurnal 


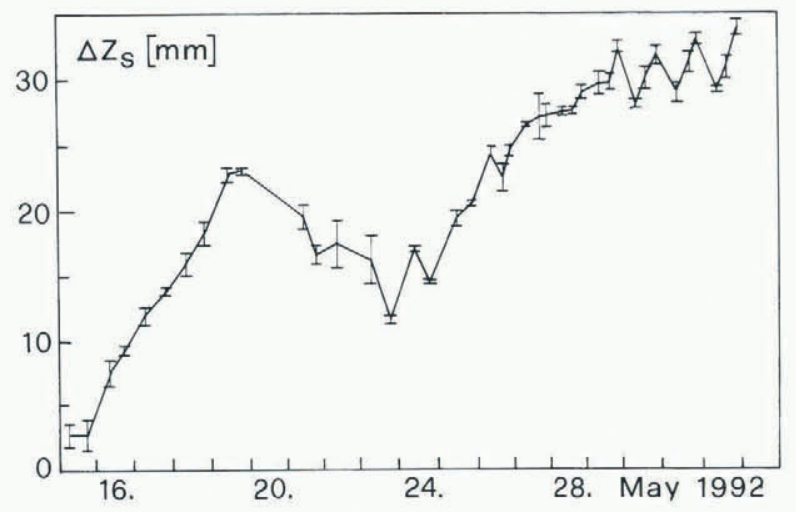

Fig. 12. Vertical displacement of pole $M$ vs time. Error bars indicate standard deviations of repeated readidngs.

variations in refraction. (We suggest that diurnal variations in surface elevation develop along with the seasonal development of the subglacial drainage system.)

$\Delta z_{\mathrm{b}}$ is inferred from Equation (2). Numerical values of $u_{\mathrm{d}}$ (deformational contribution to surface velocity) and $\beta$ (bed slope) had to be estimated. Therefore, we have examined the effect of varying these parameters over a reasonable range.

An approximate value of deformational velocity, $u_{\mathrm{d}}=0.44 \mathrm{~mm} \mathrm{~h}^{-1}$, is obtained by assuming that the sliding velocity was negligible during a period of minimum surface velocity, on 27 May (Fig. 4). Varying $u_{\mathrm{d}}$ between 0 and $0.55 \mathrm{~mm} \mathrm{~h}^{-1}$ has but a small effect on $\Delta s$. This is illustrated in Figure 13a.

The bed inclination in sliding direction cannot be inferred from Figure $1 \mathrm{~b}$ for the following reasons. First, the velocity vector nearly parallels a steep slope. A small change in azimuth is therefore accompanied by a large change in inclination. Moreover, the azimuth of the sliding motion may differ from that of the surface motion; in fact, the surface velocity vector is likely to be rotated

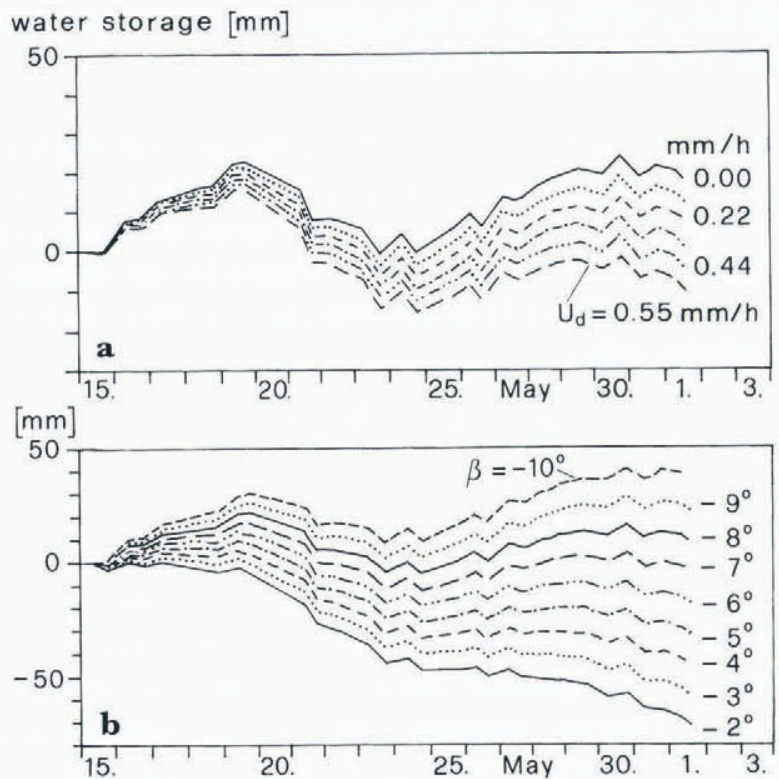

Fig. 13. Sensitivity of calculated water storage to changes in (a) assumed values of $u_{\mathrm{d}}$. Mean bed slope: $\beta=-7^{\circ}$. (b) Bed slope, $\beta$. $u_{\mathrm{d}}=0.44 \mathrm{~mm}^{-1}$. clockwise by a small angle with respect to the sliding direction at this site, because of ice flow towards the margins in the ablation area. Secondly, the distance over which the bed slope should be averaged is not known. However, it will be seen that a reasonable value of the bed slope in sliding direction is within the range of $\beta=-2^{\circ}$ to $\beta=-10^{\circ}$. The effect of varying $\beta$ over this range is depicted in Figure 1b. For $\beta=-2^{\circ}$, water storage is continuously decreasing; for $\beta=-10^{\circ}$, water storage is almost continuously increasing. Both situations are unlikely in view of the snowmelt conditions in 1992. The period 15-19 May was the first period of strong melt. It was followed by a cold period with snowfalls and subfreezing temperatures. These variations in weather conditions are reflected in the variations of water level in boreholes (Fig. 3e). Assuming an intermediate bed slope of $-6^{\circ}$ or $-7^{\circ}$ results in variations of storage which are in reasonable agreement with variations in weather conditions or water level, we have adopted $\beta=-7^{\circ}$. The choice of a constant value of $\beta$ is justified because the total distance moved during the observation period amounted to $1 \mathrm{~m}$. Small bedrock undulations are not felt at a distance of $10 \mathrm{~m}$ above the bed, the location of the magnetic ring. Note that the amplitude of fluctuations of water storage superimposed on the general trend is fairly unaffected by the choice of $\beta$.

\section{APPENDIX B}

\section{CONDITIONS FOR VARIOUS TYPES OF DAMPING}

(1) Laminar flow through one subglacial channel of radius $r$. The pressure gradient along this channel is

$$
\frac{\partial p_{\mathrm{F}}}{\partial x}=\frac{8 \eta}{r^{2}} u
$$

and the pressure drop along the total length $l$ of the subglacial channel is

$$
\Delta p_{\mathrm{F}}=\frac{8 \eta}{r^{2}} u l
$$

or, by continuity (Equation (7)),

$$
-\Delta p_{\mathrm{F}}=\frac{8 \eta}{r^{2}} \frac{r_{0}^{2}}{r^{2}} l \dot{h}_{1}=8 \eta \frac{r_{0}^{2}}{r^{4}} l \dot{h}_{1} .
$$

$\eta$ is the dynamic viscosity of water.

(2) One channel of radius $r$, rough turbulence:

$$
-\Delta p_{\mathrm{F}}=\left(\operatorname{sgn} \dot{h}_{1}\right) f_{\mathrm{r}} \frac{\rho r_{0}{ }^{4}}{4 r^{5}} l\left(\dot{h}_{1}\right)^{2}
$$

where $f_{\mathrm{r}}$ is the friction factor.

(3) Cylindrical subglacial channel branching at distances $\Delta l, 2 \Delta l, \ldots n \Delta l, \ldots .$. Laminar flow:

$$
\begin{aligned}
-\Delta p_{\mathrm{F}} & =\frac{8 \eta}{r^{2}} \dot{h}_{1}\left(\Delta l \frac{r_{0}^{2}}{r^{2}}+\Delta l \frac{r_{0}^{2}}{2 r^{2}}+\cdots \Delta l \frac{r_{0}^{2}}{2^{n} r^{2}}+\cdots\right) \\
& =\frac{8 \eta}{r^{4}} \dot{h}_{1} r_{0}^{2} \Delta l\left(\sum_{j=0}^{\infty}\left(\frac{1}{2}\right)^{j}\right)=\frac{8 \eta}{r^{4}} \dot{h}_{1} r_{0}{ }^{2}(2 \Delta l) .(\mathrm{B} 4)
\end{aligned}
$$


(4) Branching subglacial channel system, rough turbulence:

$$
\begin{aligned}
\Delta p_{\mathrm{F}} & =\left(\operatorname{sgn} \dot{h}_{1}\right) f_{\mathrm{r}} \frac{\rho}{4 r^{5}} \dot{h}_{1}{ }^{2} r_{0}{ }^{4} \Delta l \sum_{j=0}^{\infty}\left(\frac{1}{2}\right)^{2 j} \\
& =\left(\operatorname{sgn} \dot{h}_{1}\right) f_{\mathrm{r}} \frac{\rho}{4 r^{5}} \dot{h}_{1}{ }^{2} r_{0}{ }^{4}\left(\frac{4}{3} \Delta l\right) .
\end{aligned}
$$

The simplifying assumption of rough turbulence in all branches on which Equation (B5) is based, is not quite realistic: in branches, sufficiently far away from the borehole, the flow will be extremely slow and laminar. However, since more than $50 \%$ of the total frictional drag stems from flow through the first two sections $\Delta l$, the above simplification does not introduce a substantial error. More important is the frictional loss (of pressure) caused by branching and other changes in the size of cross-section. The loss at a tapered enlargement of a duct with mean flow velocity $u_{1}$ is given by

$$
\delta p_{\mathrm{E}}=K_{\mathrm{E}} \frac{\rho}{2} u_{1}^{2}\left[1-\left(\frac{A_{1}}{A_{2}}\right)^{2}\right]
$$

where $A_{1}$ is the cross-section of the duct before the enlargement, $A_{2}$ is the size of the enlarged crosssection (e.g. Barna, 1969) and $K_{\mathrm{E}}$ is a factor depending on geometry, e.g. $K_{\mathrm{E}} \approx 0.2$ for taperangles in the range of $48^{\circ}$. The loss at a branching can be expressed by an equation of the same form as Equation (B6) with $K_{\mathrm{E}}$ replaced by a slightly larger factor $K_{\mathrm{B}}$. Thus, in our model of successive branching we obtain a total pressure drop $\Delta p_{\mathrm{B}}$ due to losses at each branching which is equal to:

$$
\begin{aligned}
-\Delta p_{\mathrm{B}} & =\left(\operatorname{sgn} \dot{h}_{1}\right) \frac{4}{3} K_{\mathrm{B}} \frac{\rho}{2} \frac{r_{0}{ }^{4}}{r^{4}} \dot{h}_{1}{ }^{2}\left[1-\left(\frac{1}{2}\right)^{2}\right] \\
& =\left(\operatorname{sgn} \dot{h}_{1}\right) K_{\mathrm{B}} \frac{\rho}{2}\left(\frac{r_{0}}{r}\right)^{4}{\dot{h_{1}}}^{2} .
\end{aligned}
$$

(5) Laminar flow in radial direction through a water film at the glacier base (de Marsily, 1986, chapter 4.1) with interspersed contact areas:

$$
-\frac{\partial p_{\mathrm{F}}}{\partial R} \frac{b^{2}}{12 \eta}=\left(\operatorname{sgn} \dot{h}_{1}\right) \frac{\dot{Q}}{2 R \pi b F}
$$

where $\dot{Q}$ is the total flow through the fraction $F$ of a cylindrical section of the subglacial aquifer.

As long as there is no storage, $\dot{Q}$ is independent of $R$, which is assumed here. $\dot{Q}$ is then related to the change in height of water level in the hole by

$$
\dot{Q}=\left|\frac{\mathrm{d} h_{1}}{\mathrm{~d} t} \pi r_{0}^{2}\right| \text {. }
$$

Integration of Equation (B8) with respect to $R$ gives:

$\Delta p_{\mathrm{F}}=p\left(R_{1}\right)-p\left(R_{\mathrm{F}}\right)=-\left(\operatorname{sgn} \dot{h}_{1}\right) \frac{12 \mu \dot{Q}}{2 b^{3} \pi F} \ln \frac{R_{1}}{R_{\mathrm{F}}}$

where the integration limits are $R_{l}$, the distance from the hole where pressure remains constant, and $R_{\mathrm{F}}$, the radius of the borehole at the glacier base.
If a sediment layer is present beneath the glacier a similar equation applies:

$$
\Delta p_{\mathrm{F}}=-\left(\operatorname{sgn} \dot{h}_{1}\right) \frac{\dot{Q} \rho g}{2 \pi b K} \ln \left(\frac{R_{1}}{R_{\mathrm{F}}}\right) .
$$

Here $K$ is the hydraulic conductivity.

(6) Turbulent flow in radial direction through a water film between ice and bed:

$$
-\frac{\partial h}{\partial R}=\frac{(\operatorname{sgn} u) \dot{Q}^{2}}{(2 R \pi b F)^{2} 16 b g \ln \left(\frac{3.8}{R_{\mathrm{r}}}\right)}
$$

where $R_{\mathrm{r}}$ is the roughness defined as $R_{\mathrm{r}}=\epsilon / D_{\mathrm{h}}, \epsilon$ is the mean height of roughness elements of bedrock and glacier sole, and $D_{\mathrm{h}}$ is the hydraulic diameter of the film. In case of a thin film of large lateral extent, $D_{\mathrm{h}}$ is essentially equal to $2 b$. Equation (B10) describes the "very rough turbulent" regime and applies if $R_{\mathrm{r}}>0.035$ and if the Reynolds number

$$
\operatorname{Re}=\frac{\dot{Q} D_{\mathrm{h}} \rho}{2 F R \pi b \eta}
$$

is greater than 2300, (de Marsily, 1986, chapter 4.1).

If storage is neglected, $\dot{Q}$ is independent of $R$, and integration of Equation (B10) yields

$$
\begin{aligned}
-\Delta p_{\mathrm{F}}= & \rho g\left[h\left(R_{\mathrm{F}}\right)-h\left(R_{1}\right)\right]= \\
& (\operatorname{sgn} u) \rho\left(\frac{1}{R_{\mathrm{F}}}-\frac{1}{R_{l}}\right) \dot{Q}^{2}\left(64 b^{3} F^{2} \pi^{2} \ln \frac{3.8}{R_{\mathrm{r}}}\right) .
\end{aligned}
$$

In case of a basal sediment layer, flow near the borehole may also be turbulent, depending on the Reynolds number $\hat{R}_{\mathrm{e}}$ for flow through porous media:

$$
\hat{R}_{\mathrm{e}}=\frac{\dot{Q} \rho d}{2 \pi R b \eta}
$$

where $d$ is the grain diameter (de Marsily, 1986, p. 74). Flow becomes turbulent for $\hat{R}_{\mathrm{e}}>100$; the transition regime corresponds to the range $1<\hat{R}_{\mathrm{e}}$ $<100$. We will not consider turbulent flow through sediments here further, because this flow type was probably not encountered in the present experiments. This type of flow is included in a comprehensive treatment of slug tests inducing radial flow (Stone and Clarke, 1993).

\section{APPENDIX C}

\section{NUMERICAL ANALYSIS OF DATA}

Frequently, the natural height of water level changed during the slug experiment (Fig. 7). These changes were eliminated by fitting a regression polynomial to the curves depicting the mean height of water level as a function of time $\left(h_{0}(t)\right.$ in Fig. 7) and subtracting $h_{0}(t)$ from the data. The reduced data, $h^{*}(t)$, are then centered on $h^{*}=0$.

On the assumption that damping is turbulent, the 
differential equation of the oscillation is non-linear:

$$
\frac{\mathrm{d} \dot{h_{1}}}{\mathrm{~d} t}+\left(\operatorname{sgn} \dot{h_{1}}\right) \delta h_{1}^{2}+\omega_{0}^{2} h_{1}=0 .
$$

This equation corresponds to Equation (8) with

$$
\omega_{0}^{2}=\frac{g}{h_{0}+l \frac{r_{0}^{2}}{r^{2}}}
$$

and

$$
\delta=\frac{\left|\Delta p_{\mathrm{F}}\right|}{\rho\left(h_{0}+l \frac{r_{0}{ }^{2}}{r^{2}}\right){\dot{h_{1}}}^{2}}=\frac{\left|\Delta p_{\mathrm{F}}\right| \omega_{0}{ }^{2}}{\rho g \dot{h}_{1}{ }^{2}} .
$$

It was solved numerically using the NAG sub-routine D02EBF (a Fortran code) and varying the damping constant, $\delta$, and the undamped frequency, $\omega_{0}$, until a reasonable agreement with the measured oscillations was achieved. For example, Figure 14 shows the reduced data points, $h^{*}(t)$, together with the numerical solution, referring to the experiment on 20 May, $0900 \mathrm{~h}$.

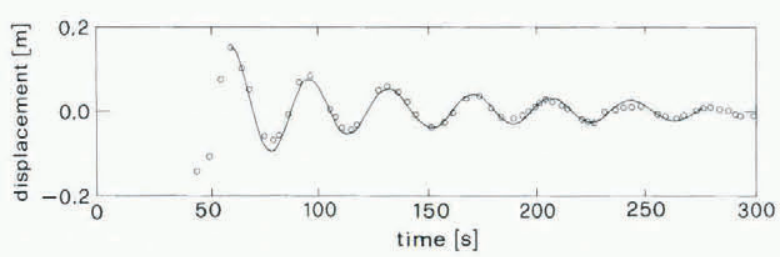

Fig. 14. Oscillation of water level in borehole 2 (Fig. Ib) after slug test on 20 May, 0900 h. Curve, numerical solution of Equation (C1) for suitable choice of constants. Circles, reduced data points, $h^{*}(t)$. 